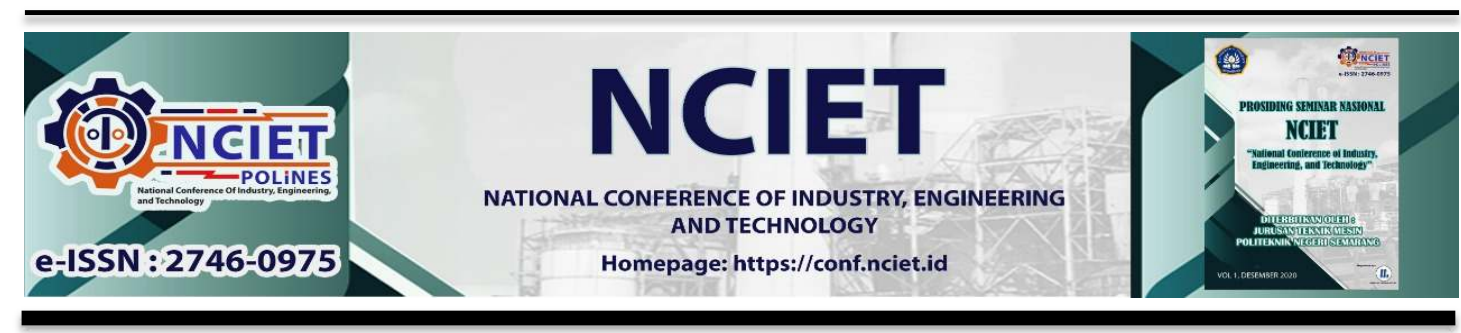

Prosiding Seminar Nasional NCIET Vol.1 (2020) B342-B349

$1^{\text {st }}$ National Conference of Industry, Engineering and Technology 2020,

Semarang, Indonesia.

\title{
METODE PENURUNAN TAHANAN PEMBUMIAN MENGGUNAKAN ELEKTRODA PLAT PARALEL DENGAN SOIL TREATMENT ARANG
}

\section{Wiwik Purwati Widyaningsih*, Margana, Wahyono, Luthfi Baharudin}

\author{
Jurusan Teknik Mesin, Politeknik Negeri Semarang \\ J1.Prof.Soedarto,SH, Tembalang, Semarang \\ *E-mail: wiwikpurwatiwidyaningsih@gmail.com
}

\begin{abstract}
Abstrak
Penelitian ini bertujuan untuk menurunkan nilai tahanan pembumian serendah mungkin dengan menggunakan elektrode plat paralel dengan soil treatment arang. Penurunan tahanan pembumian dimaksudkan supaya terhindar dari bahaya tegangan langkah, tegangan pindah dan tegangan sentuh. Penelitian ini menggunakan metode tiga titik (three point methode), dengan variasi ketinggian arang dan kedalaman penanaman $(10,20,30,40,50) \mathrm{cm}$ dan dilakukan paralel elektrode plat $1,2,3$. Hasil pengujian tahanan pembumian tanpa soil treatment arang terdapat pada kedalaman $50 \mathrm{~cm}$ elektroda plat paralel 3 sebesar 1037,6 $\Omega$ dan nilai tahanan pembumian menggunakan soil treatment arang terdapat pada kedalaman $50 \mathrm{~cm}$ elektroda plat paralel 3 sebesar $532,6 \Omega$, sehingga prosentase penurunan nilai tahanan pembumian sebesar $48,7 \%$.
\end{abstract}

Kata Kunci: Tahanan Pembumian; Plat; Paralel; Arang

\section{PENDAHULUAN}

Sistem pembumian merupakan suatu sistem yang terpenting dalam sistem tenaga listrik guna mengamankan terhadap adanya gangguan intern maupun ekstern. Gangguan tersebut dapat mengakibatkan terjadinya hubung-singkat sehingga menjadikan tidak aman dan tidak nyaman terhadap manusia maupun peralatan listrik. Ketidak nyamanan ini dapat mengakibatkan kerusakan pada peralatan listrik khususnya peralatan elektronik.

Berdasarkan Standard Nasional Indonesia (SNI), untuk gardu induk atau jaringan transmisi udara biasanya nilai grounding system nya berkisar antara $5 \Omega$ hingga $10 \Omega$. Apabila nilai tahanan pembumian masih tinggi maka perlu adanya penurunan nilai tahanan pembumian dengan cara merubah kedalaman penanaman elektroda pembumian, memperbesar diameter elektroda batang, soil treatment, memperluas luasan elektroda plat dan memparalel elektrodanya. 
Tujuan sistem pembumian berdasarkan standard IEEE std 142-2007 adalah sebagai berikut :

a. Membatasi besarnya tegangan terhadap tanah agar berada dalam batasan yang diperbolehkan

b. Menyediakan jalur bagi aliran arus yang dapat memberikan deteksi terjadinya hubungan yang tidak dikehendaki antara konduktor. Deteksi ini akan mengakibatkan beroperasinya peralatan otomatis yang memutuskan suplai tegangan dari konduktor tersebut.

Karakteristik sistem pembumian yang efektif antara lain :

a. Terencana dengan baik, semua koneksi yang terdapat pada sistem harus merupakan koneksi yang sudah direncanakan sebelumnya dengan kaidah-kaidah tertentu.

b. Verifikasi secara visual dapat dilakukan.

c. Menghindarkan gangguan yang terjadi pada arus listrik dari perangkat listrik

d. Semua komponen metal harus diikat oleh sistem pembumian (di grounding kan), dengan tujuan untuk meminimalkan arus gangguan listrik melalui material yang bersifat konduktif pada potensial listrik yang sama.

Bagian instalasi yang harus dibumikan atau di grounding kan adalah :

a. Semua bagian instalasi yang terbuat dari logam dan dengan mudah disentuh manusia. Hal ini perlu dilakukan agar potensial dari logam yang mudah disentuh manusia selalu sama dengan potensial tanah tempat manusia berpijak sehingga tidak berbahaya bagi manusia yang menyentuhnya.

b. Bagian pembuangan muatan listrik dari lightning arrester. Hal ini diperlukan agar lightning arrester berfungsi dengan baik, yaitu membuang muatan listrik yang diterimanya dari petir ke tanah dengan lancar.

c. Kawat petir yang ada pada bagian atas saluran transmisi merupakan kawat tanah yang dipasang di udara, apabila ada petir yang menyambar kawat maka petir tersebut dapat disalurkan ke dalam tanah.

d. Titik netral dari Transformator atau titik netral dari generator. Hal ini diperlukan dalam kaitan dengan keperluan proteksi khususnya yang menyangkut gangguan hubung tanah, Dalam kenyataan tahanan pembumian mempunyai nilai tahanan tidak melebihi 4 Ohm. Secara teoritis tahanan dari tanah adalah nol karena luas penampang bumi tak terhingga artinya nilai tahanan pembumian nilainya tidak nol.

e. Hal ini disebabkan oleh adanya tahanan kontak antara alat pembumian dengan tanah dimana alat tersebut terpasang dalam tanah. 
f. Sistem pembumian apabila tahanan jenisnya kecil maka nilai tahanannya akan semakin baik terutama untuk pengamanan personil maupun peralatan. Beberapa standard yang telah disepakati adalah bahwa saluran transmisi harus direncanakan nilai tahanan pembumian tidak melebihi $1 \mathrm{Ohm}$. Untuk gedung maksimum diijinkan nilai tahanan pembumian tidak melebihi $1 \mathrm{Ohm}$, untuk gedung maksimum nilai resistansi yang diijinkan 5 Ohm (PUIL 2000). Besarnya nilai tahanan pembumian elektroda yang menggunakan bahan tertentu dapat mengurangi besar tahanan pembumian.

Elektroda pembumian merupakan suatu penghantar yang sengaja ditanam di dalam tanah untuk mendapatkan tahanan kontak baik antara bagian-bagian tertentu dari instalasi listrik atau bagian-bagian yang ditanam dengan tanah. Elektroda yang digunakan untuk pembumian harus memenuhi beberapa persyaratan antara lain memiliki konduktivitas dan kekuatan mekanis yang tinggi, tahan terhadap korosi.

Nilai resistans pembumian yang rendah sering dilakukan dengan memparalel batang pembumian. Cara lain untuk memperoleh nilai resistans pembumian yang rendah pada daerah yang mempunyai nilai resistans jenis tanah yang tinggi yaitu dengan menambahkan bentonit $\left(\mathrm{Al}_{2} \mathrm{O}_{3} \cdot 4 \mathrm{SiO}_{2} \cdot 2 \mathrm{H}_{2} \mathrm{O}\right)$, kokas atau arang, garam, tepung logam, semen konduktif kedalam tanah dimana elektroda pembumian ditanam. Arang merupakan suatu bahan dari kayu yang mempunyai sifat menyerap air, juga dapat mempertahankan kelembaban tanah, hal ini disebabkan oleh kandungan air yang ada dalam arang.

Pengkondisian tanah dengan cara tersebut harus disesuaikan dengan kondisi lokasi yang akan digunakan untuk penelitian dan tergantung pada :

a. Besarnya nilai resistans tanah efektif yang dapat dicapai

b. Kemudahan untuk mendapatkan bahan.

c. Kemudahan dalam pemasangan.

d. Kemudahan dalam pemeliharaan.

e. Bahaya korosi terhadap elektrrroda batang pentanahan.

Pengaruh musim dapat mengurangi variasi resistans jenis tanah, untuk itu perlu elektroda batang tunggal pembumian yang ditanam sampai mencapai kedalaman dimana terdapat air tanah yang konstan. Sistem pembumian yang tidak mungkin atau tidak perlu elektrodanya ditanam dengan kedalaman yang lebih dalam hingga mencapai air tanah yang konstan, maka variasi resistans jenis tanah sangat besar. Apabila penanaman elektroda batang tunggal pembumian memungkinkan kelembaban dan temperatur bervariasi, nilai resistans jenis 
tanah harus diambil untuk keadaan yang paling buruk yaitu tanah kering dan dingin, nilai resistans jenis tanah tersebut biasanya diambil yang paling besar.

Berdasarkan PUIL, 2000 bahwa jenis elektroda pembumian yang dipakai ada berbagai jenis yaitu elektroda bentuk pita, elektroda bentuk bulat, elektroda bentuk pilin atau lebih dikenal elektroda bentuk plat. Untuk susunan elektroda pembumian dibedakan menjadi dua yaitu elektroda pembumian secara vertikal dan elektroda secara horisontal. Salah satu jenis elektroda yang sangat praktis digunakan adalah elektroda pembumian berpenampang bulat pejal yang diberi lapisan tembaga atau lebih dikenal dengan ground rod (batang pembumian)

Daerah-daerah yang tanahnya keras dan berbatu lebih praktis kalau menggunakan pembumian secara horisontal karena tidak memerlukan penanaman yang dalam, tetapi perlakuan khusus tanah disekitar penanaman elektroda atau lebih dikenal dengan soil treatment. Sedangkan untuk daerah yang struktur tanahnya tidak terlalu keras, pembumian secara vertikal dapat dipakai (Arismunandar, 1991).

Analisis Penambahan Arang pada Tanah untuk Menurunkan Nilai Tahanan Pembumian (S. Chandra, 2012). Dalam penelitian ini nilai tahanan pembumian dapat diturunkan dengan cepat karena mengandung kadar air berkisar ( 5-8 \% ). Penelitian yang dilakukan oleh W Purwati W, dan Kurnia Alifiana (2017) bahwa pemakaian elektroda plat dengan soil treatment gipsum dan arang, tepat untuk menurunkan tahanan pembumian pada tanah yang keras.

Metode untuk menurunkan nilai tahanan pembumian antara lain :

a. Penambahan batang elektroda pembumian atau lebih dikenal dengan paralel elektroda pentanahan, bertujuan untuk menurunkan nilai resistans tanah. Sebagai contoh paralel dua buah elektroda batang tunggal pentanahan yang akan mempunyai nilai resistans paralel (Rp) sebesar $60 \%$ dari nilai resistans elektroda batang tunggal pembumian. Paralel tiga buah elektroda batang tunggal pembumian, akan mempunyai nilai resistans sebesar $40 \%$ dari nilai resistans elektroda batang tunggal pembumian.

b. Semakin dalam penanaman elektroda batang tunggal pembumian akan menurunkan nilai resistans tanah, hal ini akibat dari semakin dekatnya kandungan embun tanah. Panjang elektroda pembumian normal $(2,5-3)$ meter.,

Menurut HB Dwight, 1936 bahwa besarnya nilai resistans pembumian :

$R=\frac{\rho}{2 \pi \cdot L}\left(\ln \frac{4 L}{a}-1\right)$

Keterangan : 
$R=$ Tahanan pembumian $(\Omega)$

$L=$ Panjang elektroda pembumian (m) $\rho=$ Tahanan jenis $(\Omega \mathrm{m})$

$\mathrm{a}=$ Jari-jari elektroda pembumian (m)

\section{METODE PENELITIAN}

Berikut diagram alir langkah pengambilan data.

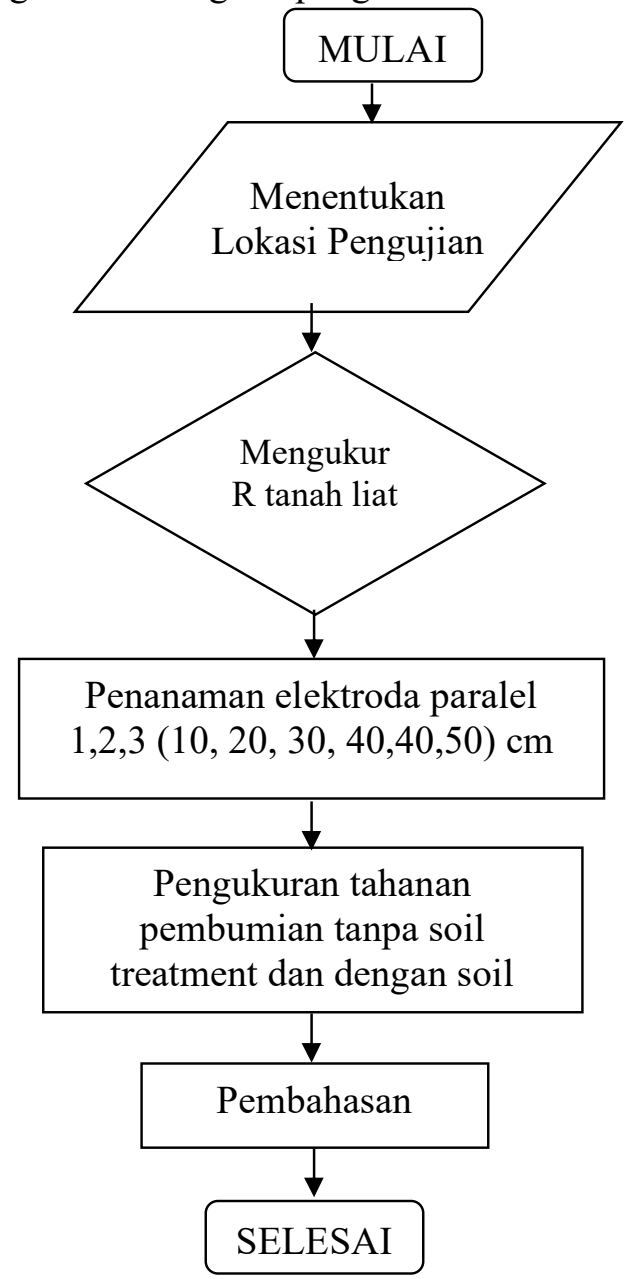

Metode penelitian yang digunakan adalah three point methode (metode tiga titik).

Langkah pengambilan data :

1. Penentuan lokasi dan waktu pengujian

2. Persiapan alat dan bahan

3. Pengukuran tahanan pembumian dengan elektroda utama plat

4. Elektroda plat di paralel 1, paralel 2, dan paralel 3

5. Kedalaman penanaman elektroda plat $(10,20,30,40,50) \mathrm{cm}$

6. Pengukuran tahanan pembumian tanpa dan dengan soil treatment pada masing-masing paralel. 


\section{HASIL DAN PEMBAHASAN}

\section{Hasil Pengujian}

Tabel 1. Nilai tahanan pembumian elektroda paralel tanpa soil treatment arang

\begin{tabular}{|c|c|c|c|c|c|c|c|c|c|}
\hline \multirow[b]{2}{*}{ NO } & \multirow[b]{2}{*}{$1(\mathrm{~cm})$} & \multirow{2}{*}{$\begin{array}{c}\text { R plat } \\
\text { tunggal } \\
(\Omega)\end{array}$} & \multirow{2}{*}{$\begin{array}{c}\text { Rata- } \\
\text { rata } \\
(\Omega)\end{array}$} & \multicolumn{6}{|c|}{ Tahanan Pembumian Paralel $(\Omega)$} \\
\hline & & & & 1 & $\begin{array}{c}\text { Rata- } \\
\text { rata }\end{array}$ & 2 & $\begin{array}{c}\text { Rata- } \\
\text { rata }\end{array}$ & 3 & $\begin{array}{c}\text { Rata- } \\
\text { rata }\end{array}$ \\
\hline \multirow{3}{*}{1} & \multirow{3}{*}{10} & 1778 & \multirow{3}{*}{1759} & 1620 & \multirow{3}{*}{1607} & 1595 & \multirow{3}{*}{1567,3} & 1412 & \multirow{3}{*}{1402,3} \\
\hline & & 1769 & & 1604 & & 1576 & & 1401 & \\
\hline & & 1730 & & 1597 & & 1531 & & 1394 & \\
\hline \multirow{3}{*}{2} & \multirow{3}{*}{20} & 1691 & \multirow{3}{*}{1665,3} & 1570 & \multirow{3}{*}{1538,3} & 1477 & \multirow{3}{*}{1456,3} & 1372 & \multirow{3}{*}{1352,3} \\
\hline & & 1667 & & 1527 & & 1461 & & 1358 & \\
\hline & & 1638 & & 1518 & & 1431 & & 1327 & \\
\hline \multirow{3}{*}{3} & \multirow{3}{*}{30} & 1575 & \multirow{3}{*}{1540,7} & 1471 & \multirow{3}{*}{1441,7} & 1381 & \multirow{3}{*}{1342,7} & 1274 & \multirow{3}{*}{904} \\
\hline & & 1537 & & 1442 & & 1340 & & 1234 & \\
\hline & & 1510 & & 1412 & & 1307 & & 1204 & \\
\hline \multirow{3}{*}{4} & \multirow{3}{*}{40} & 1489 & \multirow{3}{*}{1445} & 1388 & \multirow{3}{*}{1349} & 1279 & \multirow{3}{*}{1247} & 1175 & \multirow{3}{*}{1151} \\
\hline & & 1435 & & 1350 & & 1248 & & 1155 & \\
\hline & & 1411 & & 1309 & & 1214 & & 1123 & \\
\hline \multirow{3}{*}{5} & \multirow{3}{*}{50} & 1374 & \multirow{3}{*}{1341,7} & 1272 & \multirow{3}{*}{1242,7} & 1167 & \multirow{3}{*}{1132} & 1073 & \multirow{3}{*}{1037,7} \\
\hline & & 1341 & & 1245 & & 1127 & & 1035 & \\
\hline & & 1310 & & 1211 & & 1102 & & 1005 & \\
\hline
\end{tabular}

Tabel 2. Nilai tahanan pembumian elektroda paralel dengan soil treatment arang

\begin{tabular}{|c|c|c|c|c|c|c|c|c|c|}
\hline \multirow[b]{2}{*}{ NO } & \multirow[b]{2}{*}{$1(\mathrm{~cm})$} & \multirow{2}{*}{$\begin{array}{c}\text { R plat } \\
\text { tunggal } \\
(\Omega)\end{array}$} & \multirow{2}{*}{$\begin{array}{c}\text { Rata- } \\
\text { rata } \\
(\Omega)\end{array}$} & \multicolumn{6}{|c|}{ Tahanan Pembumian Paralel $(\Omega)$} \\
\hline & & & & 1 & $\begin{array}{l}\text { Rata- } \\
\text { rata }\end{array}$ & 2 & $\begin{array}{c}\text { Rata- } \\
\text { rata }\end{array}$ & 3 & $\begin{array}{c}\text { Rata- } \\
\text { rata }\end{array}$ \\
\hline \multirow{3}{*}{1} & \multirow{3}{*}{10} & 1270 & \multirow{3}{*}{1241,3} & 1171 & \multirow{3}{*}{1141} & 1070 & \multirow{3}{*}{1037} & 971 & \multirow{3}{*}{937,7} \\
\hline & & 1251 & & 1146 & & 1040 & & 942 & \\
\hline & & 1203 & & 1106 & & 1001 & & 900 & \\
\hline \multirow{3}{*}{2} & \multirow{3}{*}{20} & 1164 & \multirow{3}{*}{1129,3} & 1065 & \multirow{3}{*}{1030,7} & 965 & \multirow{3}{*}{934} & 855 & \multirow{3}{*}{826,3} \\
\hline & & 1122 & & 1026 & & 930 & & 824 & \\
\hline & & 1102 & & 1001 & & 907 & & 800 & \\
\hline \multirow{3}{*}{3} & \multirow{3}{*}{30} & 1063 & \multirow{3}{*}{1035,3} & 957 & \multirow{3}{*}{929,7} & 863 & \multirow{3}{*}{834} & 771 & \multirow{3}{*}{738,7} \\
\hline & & 1036 & & 927 & & 831 & & 739 & \\
\hline & & 1007 & & 905 & & 808 & & 706 & \\
\hline \multirow{3}{*}{4} & \multirow{3}{*}{40} & 967 & \multirow{3}{*}{931,3} & 863 & \multirow{3}{*}{832,3} & 767 & \multirow{3}{*}{734,7} & 650 & \multirow{3}{*}{627,7} \\
\hline & & 926 & & 828 & & 731 & & 630 & \\
\hline & & 901 & & 806 & & 706 & & 603 & \\
\hline \multirow{3}{*}{5} & \multirow{3}{*}{50} & 869 & \multirow{3}{*}{835,3} & 766 & \multirow{3}{*}{731,3} & 658 & \multirow{3}{*}{628,7} & 561 & \multirow{3}{*}{532,7} \\
\hline & & 832 & & 728 & & 622 & & 529 & \\
\hline & & 805 & & 700 & & 606 & & 508 & \\
\hline
\end{tabular}

Tabel 1. Tanpa soil treatment bahwa rata-rata nilai tahanan pembumian elektroda plat tunggal paling besar sebesar $1759 \Omega$ dengan kedalaman $10 \mathrm{~cm}$ dan paling kecil sebesar 
1341,7 $\Omega$ dengan kedalaman $50 \mathrm{~cm}$. Rata-rata nilai tahanan pembumian elektroda plat paralel 1 paling besar sebesar $1607 \Omega$ pada kedalaman $10 \mathrm{~cm}$ dan paling kecil sebesar 1242,7 $\Omega$ kedalaman $50 \mathrm{~cm}$. Rata-rata nilai tahanan pembumian elektroda plat paralel 2 paling besar sebesar $1567,3 \Omega$ pada kedalaman $10 \mathrm{~cm}$ dan paling kecil sebesar $1132 \Omega$ dengan kedalaman $50 \mathrm{~cm}$. Rata-rata nilai tahanan pembumian elektroda plat paralel 3 paling besar 1402,3 $\Omega$ pada kedalaman $10 \mathrm{~cm}$ dan paling kecil sebesar 1037,6 $\Omega$ dengan kedalaman $50 \mathrm{~cm}$.

Tabel 2. Dengan soil treatment bahwa rata-rata nilai tahanan pembumian elektroda plat tunggal paling besar sebesar 1241,3 $\Omega$ dengan kedalaman $10 \mathrm{~cm}$ dan paling kecil sebesar $835,3 \Omega$ dengan kedalaman $50 \mathrm{~cm}$. Rata-rata nilai tahanan pembumian elektroda plat paralel 1 paling besar sebesar $1141 \Omega$ pada kedalaman $10 \mathrm{~cm}$ dan paling kecil sebesar 731,3 $\Omega$ kedalaman $50 \mathrm{~cm}$. Rata-rata nilai tahanan pembumian elektroda plat paralel 2 paling besar sebesar $1037 \Omega$ pada kedalaman $10 \mathrm{~cm}$ dan paling kecil sebesar $628,7 \Omega$ dengan kedalaman $50 \mathrm{~cm}$. Rata-rata nilai tahanan pembumian elektroda plat paralel 3 paling besar 937,7 $\Omega$ pada kedalaman $10 \mathrm{~cm}$ dan paling kecil sebesar $532,7 \Omega$ dengan kedalaman $50 \mathrm{~cm}$.

\section{KESIMPULAN}

Berdasarkan data pengujian pada tabel 1 dan tabel 2 dapat disimpulkan bahwa penambahan soil treatment dan kedalaman penanaman elektrode plat serta paralel elektrode dapat mempengaruhi prosentase penurunan nilai tahanan pembumian elektroda plat :

1. Prosentase penurunan tahanan pembumian elektroda plat $29,4 \%$ pada kedalaman $10 \mathrm{~cm}$ dan $37,7 \%$ untuk kedalaman $50 \mathrm{~cm}$.

2. Prosentase penurunan tahanan pembumian elektroda plat paralel satu $29 \%$ pada kedalaman $10 \mathrm{~cm}$ dan $41,2 \%$ untuk kedalaman $50 \mathrm{~cm}$.

3. Prosentase penurunan tahanan pembumian elektroda plat paralel satu $29 \%$ pada kedalaman $10 \mathrm{~cm}$ dan $41,2 \%$ untuk kedalaman $50 \mathrm{~cm}$.

4. Prosentase penurunan tahanan pembumian elektroda plat paralel dua $33,8 \%$ pada kedalaman $10 \mathrm{~cm}$ dan $44,5 \%$ untuk kedalaman $50 \mathrm{~cm}$.

5. Prosentase penurunan tahanan pembumian elektroda plat paralel tiga $33,1 \%$ pada kedalaman $10 \mathrm{~cm}$ dan $48,7 \%$ untuk kedalaman $50 \mathrm{~cm}$.

6. Semakin dalam penanaman elektroda plat semakin rendah nilai tahanan pembumian, hal ini diakibatkan oleh semakin dekat dengan sumber mata air

7. Semakin banyak paralel elektrodanya maka nilai tahanan pembumian semakin rendah 
8. Penambahan soil treatment dapat mengakibatkan nilai tahanan pembumian semakin rendah, karena tanah semakin lembab.

\section{DAFTAR PUSTAKA}

Abidin, Zainal, Suharijanto, Ghufron Abdul. 2016. “Analisa Sistem Pentanahan Instalasi Listrik di Tanah Kapur dan Padas Menggunakan Metode Sigarang ( Sistem Grounding Arang dan Garam )" dalam Jurnal Program Studi Teknik Elektro JE-Unisla ISSN : 2502-0986, ( hlm 2 ). Lamongan: Universitas Islam Lamongan

Anggara, Putro. 2015. "Analisis Pengaruh Penggunaan Soil Treatment dengan Menggunakan Arang Terhadap Elektroda Plat untuk Menurunkan Tahanan Pembumian”. Tugas Akhir. Semarang:Politeknik Negeri Semarang

Dedy, Lucky. 2013. "Studi Pemanfaatan Tempurung Kelapa untuk Perbaikan Resistansi Pembumian Jenis Elektroda Batang”. Skripsi. Malang: Universitas Brawijaya

Ponadi, Acep. 2014. "Analisis Perbandingan Nilai Tahanan Pentanahan Menggunakan Elektroda Batang $(R O D)$ Jenis Crom Tembaga, Allumunium, Besi, dengan Media Tanah Pasir Lumpur dan Tanah Liat" dalam jurnal Ilmiah Mustek Anim volume 3 No. 2 ( hlm 175 ). Merauke: Universitas Musamus

Purwati, Wiwik, \& dkk. 2017. "Penurunan Tahanan Pembumian dengan Menggunakan Campuran Gypsum dan Arang pada Elektroda Plat" dalam EKSERGI Jurnal Teknik Energi Volume 13 No. 3 (hlm. 103-106). Semarang: Politeknik Negeri Semarang

Satriyo, Chandra. 2012. "Analisis Penambahan Arang pada Tanah untuk Menurunkan Nilai Tahanan Pembumian". Tugas Akhir. Semarang: Politeknik Negeri Semarang

Setiawan, Deni, dkk. 2018. "Analisis Pengaruh Penambahan Garam dan Arang sebagai Soil Treatment dalam Menurunkan Resistansi Pentanahan Variasi Kedalaman Elektroda" dalam TRANSIENT ejournal3.undip.ac.id Volume 7 No. 2, ISSN: 2302-9927, ( hlm 417 ). Semarang: Universitas Diponegoro 